\title{
Epineural ganglion causing cubital tunnel syndrome: A case report
}

\author{
Nazmi Bülent Alp, MD (D), Gökhan Akdağ, MD(D) \\ Department of Orthopedics and Traumatology, Istanbul Bahçelievler State Hospital, Istanbul, Turkey
}

The ulnar nerve consists of $\mathrm{C} 8$ and $\mathrm{T} 1$ nerve roots forming the terminal branch of the medial cord of brachial plexus. Entrapment of ulnar nerve at elbow is known as cubital tunnel syndrome (CuTS), which is the most common compression neuropathy after the carpal tunnel. ${ }^{[1]}$ Etiologic factors that may cause nerve compression are arthritis, spaceoccupying lesions, heterotopic ossification, recurrent occupational trauma, and metabolic conditions such as diabetes and alcoholism..$^{[2]}$ Clinical diagnosis of CuTS remains the gold standard, and nerve conduction studies support to confirm diagnosis. Many studies advocate the reduction of motor conductivity along elbow to confirm the diagnosis of CuTS. Less than 50 meters per second or relative motor conduction velocity decrease of $33 \%$ is thought to be indicative of CuTS.

Space-occupying lesions, like ganglions, are rare causes of the CuTS ${ }^{[3]}$ Even though the ganglions are histologically defined as benign tumors, possible permanent neurological damage may happen in case of compression of the nerve or invasion. ${ }^{[4]}$ In this article, we report a patient who had CuTS due to epineural ganglion and was treated with simple ulnar nerve decompression and excision of the epineural ganglion. ${ }^{[5]}$

Received: June 12, 2019

Accepted: October 23, 2019

Published online: March 02, 2020

Correspondence: Nazmi Bülent Alp, MD. Bursa Şehir Hastanesi Ortopedi ve Travmatoloji Kliniği, 16110 Doğanköy, Nilüfer, Bursa, Türkiye.

E-mail: nazmibulentalp@hotmail.com

Doi: $10.5606 /$ ehc. 2020.66993

Citation: Alp NB, Akdağ G. Epineural ganglion causing cubital tunnel syndrome: A case report. Jt Dis Relat Surg 2020;31(1):154-158.

\section{ABSTRACT}

Although ganglions are the most common cause of ulnar tunnel syndrome, they are one of the rare causes of cubital tunnel syndrome (CuTS). In this article, we report a 49-year-old female patient admitted to the outpatient clinic complaining of numbness and tingling in the ring and little fingers of the right hand. There was no history of systemic disease or previous trauma. The patient was diagnosed with CuTS in the light of clinical examination and nerve conduction studies. Simple cubital tunnel decompression was performed under general anesthesia and microsurgical exploration revealed a $2 \times 2 \mathrm{~cm}$ epineural ganglion cyst compressing the ulnar nerve. The cyst was excised without damaging the ulnar nerve and cutaneous nerves. Histopathology also confirmed the ganglion cyst. In the postoperative period, the patient's clinical improvement was more satisfactory than nerve conduction studies. The diagnosis of CuTS is established by physical examination, provocative test, and nerve conduction studies. In patients who cannot achieve a satisfactory outcome by conservative treatment, the cyst should be kept in mind among etiologic factors. Magnetic resonance imaging should be requested for accurate diagnosis and preoperative surgical planning.

Keywords: Cubital tunnel syndrome, epineural ganglion, ulnar nerve.

\section{CASE REPORT}

A 49-year-old female patient admitted to the outpatient clinic with complaints of continuous numbness and tingling in the ring and little fingers of the right hand for nine months. She had no previous history of upper extremity injury or no systemic disease such as Guillain-Barre or amyotrophic lateral sclerosis. The patient had a positive Tinel sign and palpation showed tenderness in the retrocondylar groove without ulnar nerve instability. No palpable mass was detached. During physical examination, patient's intrinsic muscle strength was decreased, adduction of little finger was also decreased, while neither clawing nor Wartenberg sign was observed. Pseudo Froment sign was also detected. According to static and moving 
two-point discrimination test, the sensation of the fifth and half of the fourth finger was decreased. Elbow range of motion demonstrated full extension, full flexion, pronation, and supination, and no joint instability was examined. Diagnosis of CuTS was established clinically and nerve conduction studies were performed before and after surgery (Figures 1, 2, and 3). Cervical magnetic resonance imaging (MRI) was requested to eliminate cervical disc disease and elbow anteroposterior/ lateral X-rays to eliminate arthritis. The patient underwent simple surgical decompression for CuTS, and microsurgical exploration revealed $3 \times 2 \mathrm{~cm}$ epineural ganglion, which was not extending to the Osborne fascia and compressing the ulnar nerve (Figures 4 and 5). The ganglia was excised without further damage to ulnar nerve or nearby cutaneous nerves and its branches (Figure 6). Histopathology revealed a ganglion cyst. A written informed consent was obtained from the patient.
During postoperative follow-up, shoulder, elbow, wrist, and finger movements were taught to the patient for physical therapy purposes. She was advised to wear a shoulder arm strap to limit elbow extension at night. We restricted heavy lifting for one month. Strengthening exercises began four weeks after surgery. The patient was allowed full activity and returned to work without restrictions eight weeks after surgery. During the first two months of the postoperative period, the patient had dramatic pain relief. During postoperative period, patient was revisited six months later. The nerve conduction study showed minimum improvement in latency, and further nerve conduction studies were not accepted by the patient. There was no recurrence of the ganglion for up to two years of follow-up.

\section{DISCUSSION}

The ulnar nerve entrapment in the cubital tunnel is the second most common nerve entrapment

1ch: Right, abductor digiti minimi, ulnaris, C8 T1

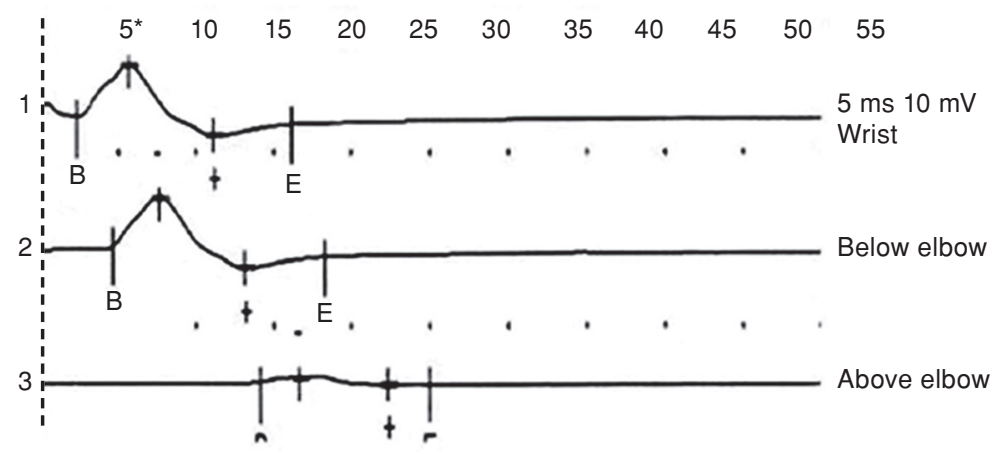

\begin{tabular}{|c|l|c|c|c|c|c|c|c|}
\hline \multicolumn{1}{|l|}{ M-wawe parameters } \\
\hline $\mathrm{n}$ & Stim. point & $\begin{array}{c}\text { Lat., } \\
(\mathrm{ms})\end{array}$ & $\begin{array}{c}\text { Dur., } \\
(\mathrm{ms})\end{array}$ & $\begin{array}{c}\text { Ampl., } \\
(\mathrm{mV})\end{array}$ & $\begin{array}{c}\text { Square, } \\
\left(\mathrm{mV} \mathrm{ms}^{*}\right.\end{array}$ & $\begin{array}{c}\text { Dist., } \\
(\mathrm{mm})\end{array}$ & $\begin{array}{c}\text { Stim.., } \\
(\mathrm{mA})\end{array}$ & $\begin{array}{c}\text { Stim.., } \\
(\mu \mathrm{s})\end{array}$ \\
\hline 1 & Wrist & 2.35 & 13.8 & 4.21 & 15 & 0 & 65 & 200 \\
\hline 2 & Below elbow & 4.65 & 13.7 & 4.23 & 15.6 & 130 & 65 & 200 \\
\hline 3 & Above elbow & 14.2 & 10.8 & 0.58 & 2.15 & 300 & 67 & 200 \\
\hline
\end{tabular}

\begin{tabular}{|c|c|c|c|c|c|c|}
\hline \multicolumn{7}{|c|}{ Motor segment CV } \\
\hline $\mathrm{n}$ & Stim. point & $\begin{array}{l}\text { Dist., } \\
(\mathrm{mm})\end{array}$ & $\begin{array}{c}\text { Interval } \\
\text { (ms) }\end{array}$ & $\begin{array}{l}\text { Vel., } \\
(\mathrm{m} / \mathrm{s})\end{array}$ & $\begin{array}{l}\text { Vel. norm, } \\
(\mathrm{m} / \mathrm{s})\end{array}$ & $\begin{array}{l}\text { Vel. dev., } \\
(\%)\end{array}$ \\
\hline $1-2$ & Wrist-below elbow & 130 & 2.3 & 56.5 & 60 & (n) \\
\hline $2-3$ & Below elbow-above elbow & 170 & 9.5 & 17.9 & 60 & -70.2 \\
\hline $1-3$ & Wrist-above elbow & 300 & 11.8 & 25.4 & 60 & -57.6 \\
\hline
\end{tabular}

FIGURE 1. Preoperative nerve conduction study showing velocity decrease. 


\begin{tabular}{|l|c|c|c|}
\hline \multicolumn{4}{|l|}{ Right Ulnaris Motor } \\
\cline { 2 - 4 } & Lat & Amp & $\mathrm{CV}$ \\
\hline Wrist-ADM & $\mathrm{ms}$ & $\mathrm{mV}$ & $\mathrm{m} / \mathrm{s}$ \\
\hline Below elbow-wrist & 7.30 & 1.33 & \\
\hline Above elbow-below elbow & 10.3 & 0.98 & 50.0 \\
\hline
\end{tabular}

Right ulnaris

Wrist-ADM

$3 \mathrm{mV} / \mathrm{D} 3 \mathrm{~ms} / \mathrm{D}$

Bl. elbow-ADM

$3 \mathrm{mV} / \mathrm{D} 3 \mathrm{~ms} / \mathrm{D}$

Ab. elbow-ADM

$3 \mathrm{mV} / \mathrm{D} 3 \mathrm{~ms} / \mathrm{D}$

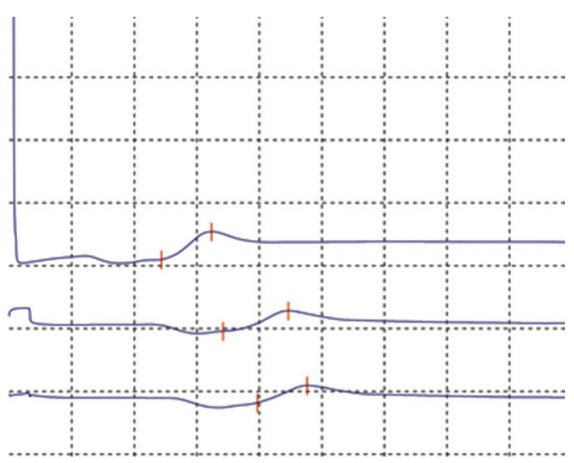

FIGURE 2. Early postoperative nerve conduction study showing velocity increase.

Lat: Latency; ms: Millisecond; Amp: Amplitude; mV: Millivolt; CV: Conduction velocity; m/s: Meter per second; ADM: Abductor digiti minimi.

\begin{tabular}{|l|c|c|c|}
\hline \multicolumn{4}{|l|}{ Right UInaris Motor } \\
\cline { 2 - 4 } & Lat & $\mathrm{Amp}$ & $\mathrm{CV}$ \\
\hline Wrist-ADM & $\mathrm{ms}$ & $\mathrm{mV}$ & $\mathrm{m} / \mathrm{s}$ \\
\hline Below elbow-wrist & 6.12 & 2.2 & \\
\hline Above elbow-below elbow & 8.89 & 1.32 & 61.4 \\
\hline
\end{tabular}

Right Ulnaris

Wrist-ADM $5 \mathrm{mV} / \mathrm{D} 3 \mathrm{~ms} / \mathrm{D}$ Below elbow-ADM $5 \mathrm{mV} / \mathrm{D} 3 \mathrm{~ms} / \mathrm{D}$

Above elbow-ADM $5 \mathrm{mV} / \mathrm{D} 3 \mathrm{~ms} / \mathrm{D}$

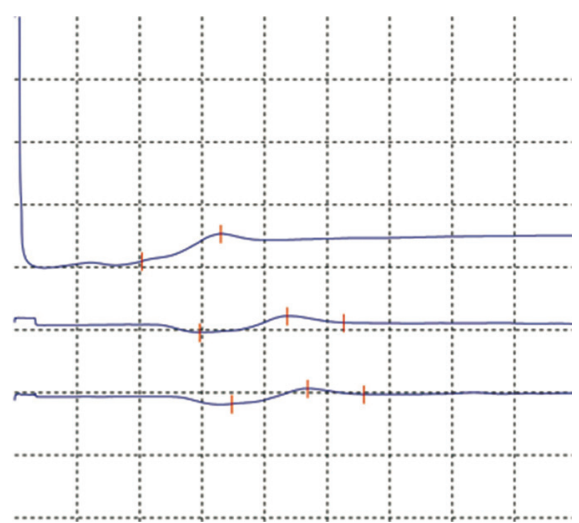

FIGURE 3. Late postoperative nerve conduction study showed improved velocity.

Lat: Latency; ms: Millisecond; Amp: Amplitude; mV: Millivolt; CV: Conduction velocity; m/s: Meter per second; ADM: Abductor digiti minimi.

syndrome after trapping of the median nerve in the carpal tunnel. ${ }^{[6]}$ Generally, a diagnosis of CuTS is primarily based on clinical examination while nerve conduction studies help to confirm diagnosis. There are many etiological factors associated with CuTS including fractures, dislocations, direct soft

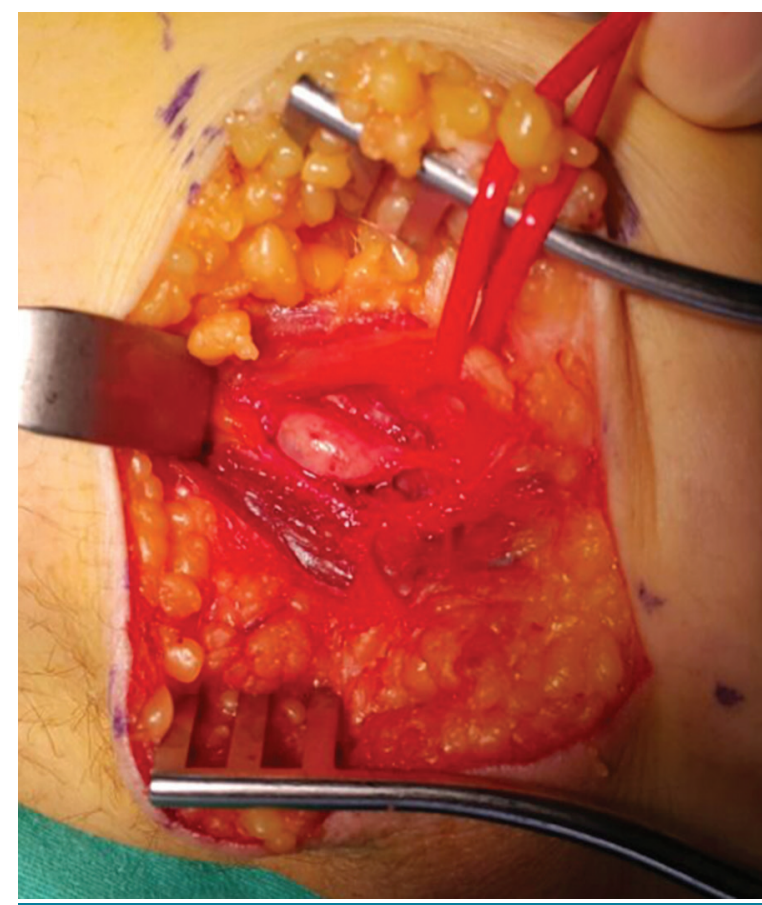

FIGURE 4. Intraoperative photograph of epineural ganglion sized approximately $1.5 \times 2.5 \times 2 \mathrm{~cm}$, compressed the underlying ulnar nerve.

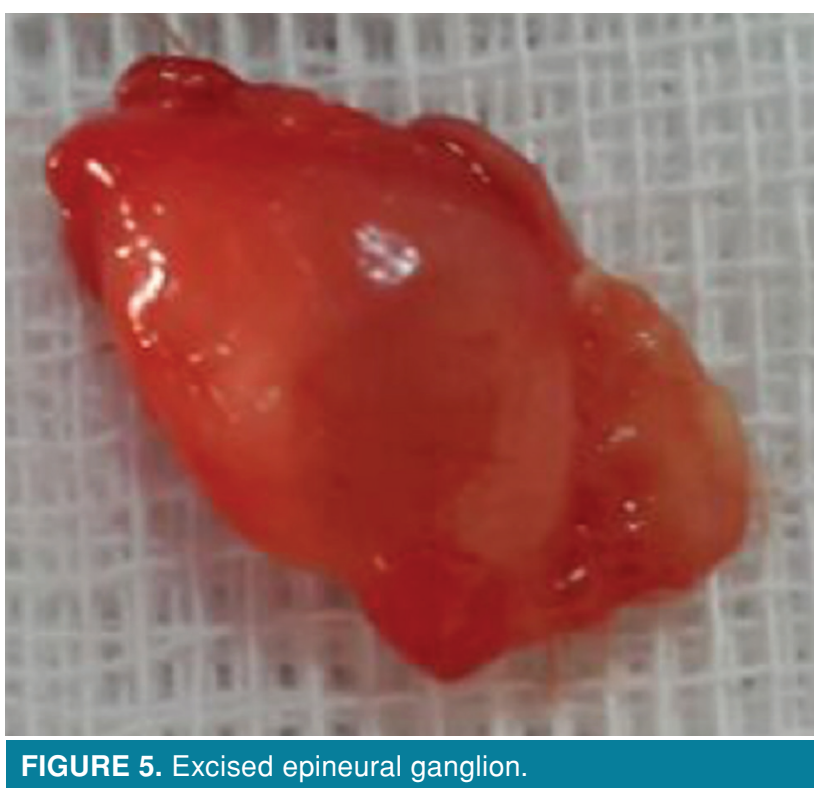

tissue trauma, arthritis, heterotopic ossification, soft tissue masses, metabolic conditions predisposing to neuropathy such as diabetes, alcoholism, external compression and occupations that require repetitive or persistent elbow flexion. As a primary causative factor, ganglions are rare to develop CuTS. Kato et al. ${ }^{[7]}$ 


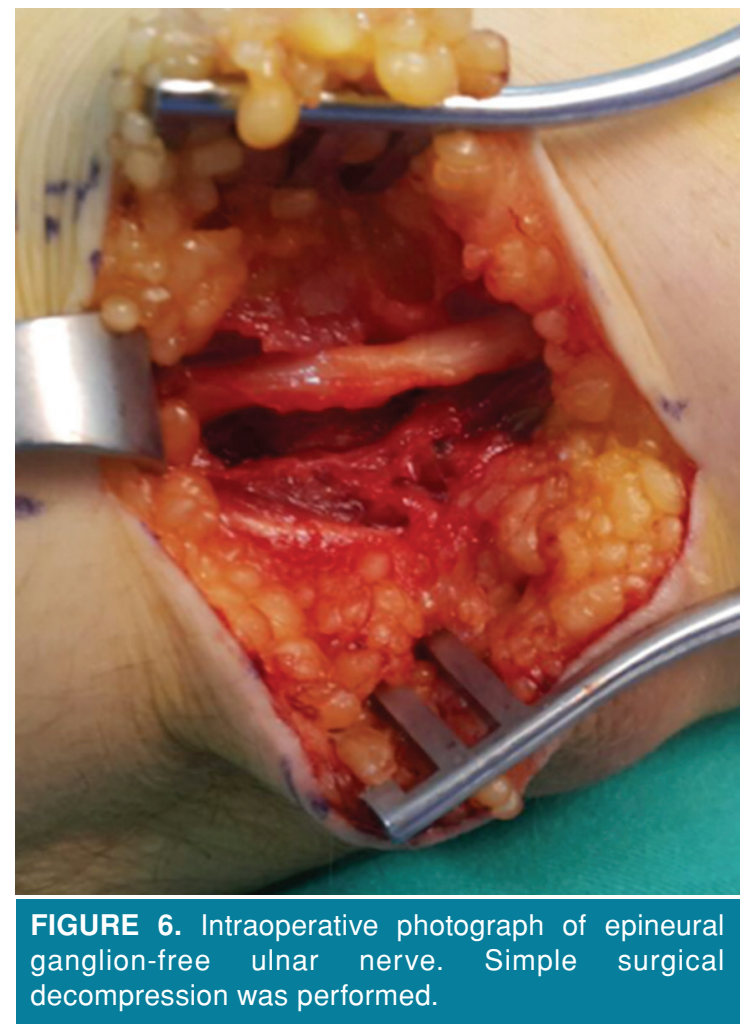

reported the largest CuTS series in the literature in which they investigated 472 patients retrospectively. They reported that 38 patients were operated for medial ganglion. However, when they examined the roentgenograms of those patients, they found that 37 of the medial ganglions had developed secondary to elbow arthritis. Apart from this article, only case reports have been reported in the literature. ${ }^{[8-15]}$

Ganglions can be separated as being intraneural and extraneural. Whether extraneural or intraneural, if lesions compress the ulnar nerve, they should be diagnosed rapidly and removed immediately without causing any permanent damage. Although many techniques such as subcutaneous transposition, intramuscular transposition, and muscular transposition of the ulnar nerve have been well described, in the present case, we preferred simple surgical decompression. The surgeon may choose the suitable method for the case during the intraoperative microsurgical exploration.

In the majority of the cases and in our case, the etiology was not clear until the time of surgical intervention. Since MRI is an inexpensive and widely-used imaging method, we recommended it for preoperative diagnosis in patients with CuTS to understand the etiology better and decide on short or long segment decompression during surgery. Komatsu et al. ${ }^{[15]}$ reported that as ganglions are generally not palpable, they recommended MRI for accurate diagnosis of CuTS as we did. In addition, Pham et al. ${ }^{[16]}$ also advocated the usage of MRI in case of ganglions and lipomas as a cause of CuTS. Early diagnosis may result in less damage to the nerve, early recovery of hand functions, and quicker recovery in electrophysiological parameters. ${ }^{[17]}$ In our case, the late admittance to the outpatient clinic and prolonged compression may explain the slower recovery of the nerve conduction study parameters.

\section{Declaration of conflicting interests}

The authors declared no conflicts of interest with respect to the authorship and/or publication of this article.

\section{Funding}

The authors received no financial support for the research and/or authorship of this article.

\section{REFERENCES}

1. Yoon JS, Walker FO, Cartwright MS. Ulnar neuropathy with normal electrodiagnosis and abnormal nerve ultrasound. Arch Phys Med Rehabil 2010;91:318-20.

2. Lowe JB 3rd, Novak CB, Mackinnon SE. Current approach to cubital tunnel syndrome. Neurosurg Clin N Am 2001;12:267-84.

3. Kuschner SH, Gelberman RH, Jennings C. Ulnar nerve compression at the wrist. J Hand Surg Am 1988;13:577-80.

4. Tindall SC. Ganglion cysts of peripheral nerves. In: Wilkins RH, Rengachary SS, editors. Neurosurgery. 2nd ed. New York: Mc Graw-Hill; 1996. p. 3225.

5. Atik OŞ. Is there something new and interesting in my article? Eklem Hastalik Cerrahisi 2019;30:69.

6. An TW, Evanoff BA, Boyer MI, Osei DA. The prevalence of cubital tunnel syndrome: A Cross-Sectional Study in a U.S. Metropolitan Cohort. J Bone Joint Surg [Am] 2017;99:408-16.

7. Kato H, Hirayama T, Minami A, Iwasaki N, Hirachi K. Cubital tunnel syndrome associated with medial elbow Ganglia and osteoarthritis of the elbow. J Bone Joint Surg [Am] 2002;84:1413-9.

8. Ferlic DC, Ries MD. Epineural ganglion of the ulnar nerve at the elbow. J Hand Surg Am 1990;15:996-8.

9. Hsu RW, Chen CY, Shen WJ. Ulnar nerve palsy due to concomitant compression by the anconeus epitrochlearis muscle and a ganglion cyst. Orthopedics 2004;27:227-8.

10. Ming Chan K, Thompson S, Amirjani N, Satkunam L, Strohschein FJ, Lobay GL. Compression of the ulnar nerve at the elbow by an intraneural ganglion. J Clin Neurosci 2003;10:245-8.

11. Li P, Lou D, Lu H. The cubital tunnel syndrome caused by intraneural ganglion cyst of the ulnar nerve at the elbow: a case report. BMC Neurol 2018;18:217.

12. Boursinos LA, Dimitriou CG. Ulnar nerve compression in the cubital tunnel by an epineural ganglion: a case report. Hand (N Y) 2007;2:12-5.

13. Sharma RR, Pawar SJ, Delmendo A, Mahapatra AK. Symptomatic epineural ganglion cyst of the ulnar nerve 
in the cubital tunnel: a case report and brief review of the literature. J Clin Neurosci 2000;7:542-3.

14. Sinha S, Pinder RM, Majumder S. The largest reported epineural ganglion of the ulnar nerve causing cubital tunnel syndrome: case report and review of the literature. J Plast Reconstr Aesthet Surg 2013;66:e23-5.

15. Komatsu M, Uchiyama S, Kimura T, Suenaga N, Hayashi M, Kato H. Recurrent cubital tunnel syndrome caused by ganglion: A report of nine cases. J Hand Surg Asian Pac Vol 2018;23:210-6.

16. Pham M, Bendszus M. MRI as an additional diagnostic tool for the cubital tunnel syndrome. Handchir Mikrochir Plast Chir 2009;41:18-22.

17. Allieu PY, Cenac PE. Peripheral nerve mucoid degeneration of the upper extremity. J Hand Surg Am 1989;14:189-94. 